\title{
Power Flow Control by Unified Power Flow Controller
}

\author{
Muhammad Yousaf Ali Khan
Department of Electrical Engineering \\ Muhammad Yousaf Ali Khan
Department of Electrical Engineering, \\ Gomal University, \\ D. I. Khan, Pakistan \\ myousafak@gu.edu.pk
}

\author{
Hamayun Khan \\ Department of Electrical Engineering, \\ Gomal University, \\ D. I. Khan, Pakistan \\ hamayunkhan@gu.edu.pk
}

\author{
Amad Uddin \\ Department of Electronic Engineering, \\ Fatima Jinnah Women University, \\ Rawalpindi, Pakistan \\ ammad@fjwu.edu.pk
}

\author{
Sheeraz Ahmed \\ School of Computer Science, \\ Iqra National University, \\ Peshawar, Pakistan \\ Sheerazahmed306@gmail.com
}

\begin{abstract}
The demand for electricity is increasing day by day and we have to produce more electrical energy to meet the load demands. Most of the experts prefer to extend the existing electrical networks over building the new network with greater costs. In this paper, the implementation of the flexible AC transmission systems (FACTS) devices in a simple electrical network is described. FACTS devices enhance power transfer capacity of the line without laying out new transmission line. These devices also protect the system from overloading in case of any contingency in the electrical network. Moreover, this paper describes the impacts of FACTS devices on improving the voltage stability and power handling capability of a transmission line. The proposed methods for the controllable flow of active and reactive power in a transmission line are also elaborated. A simple electrical system is examined to explain the improvement in the constraints of power system using FACTS devices.
\end{abstract}

Keywords-flexible AC transmission systems (FACTS); genetic algorithm (GA); phase shifting transformer (PST); static VAR compensator (SVC); static compensator (STATCOM)

\section{INTRODUCTION}

Modern-day power systems are heavily stressed because of the growing demand for electricity and the competition in the electricity market [1]. Nowadays, there is a huge difference between the supply and demand for electricity. Power shortages occur due to the increasing population and improved living standards. A solution in these problems is to increase power generation and decrease power losses. Any increase in power generation demands new transmission lines which require high capital investments. Although the existing transmission networks operate near their rated capacity, yet there is some flexibility in increasing the power handling capacity of the existing transmissions lines. Flexible AC transmission systems (FACTS) are power electronic based semiconductor devices used to enhance the power handling capability of the transmission lines [2]. The main capabilities of
FACTS devices are to control power flow, reactive power compensation and voltage control. The installation of a new electrical network or extending the existing one requires a high capital cost. FACTS controllers save this capital by improving the constraints of the power system [3]. FACTS controllers utilize the existing electrical network to its maximum capacity. In the past, VAR generators were connected to improve the voltage profiles of the electrical networks thus improving the performance of the network.

Reliability and quality of the supplied power to the customers are improved by using VAR compensators [2]. In different contingency conditions, FACTS devices can be used to improve the static voltage stability margin of the system. The loading margin of the transmission line can be increased to its maximum capacity by the use of unified power flow controller UPFC [4]. SVCs and STATCOMs show better performance in terms of improving voltage profile and reducing line transmission losses [5]. Although shunt capacitors serve the same purpose and are less expensive, they are rarely used because of their operation time. A substation is used to transport the electric energy from a producer $\mathrm{A}$ to a load center B located at a specific distance. The consumer can be supplied through a number of transmission lines. The problem of uncontrolled power flows between the transmission lines occurs in these types of systems. Moreover, the transmission lines are loaded unevenly under these conditions. Active power can be regulated in the power system through phase shifting transformers (PSTs) [6]. The voltage instability in a power system is caused by the imbalance of reactive power. When an electrical system tends to approach its operating limits the loss of real and reactive power increases rapidly. Thus, in order to obtain voltage stability, reactive power must have to be supplied locally and adequately. The application of FACTS controllers enhances voltage stability and the loading margin of the system. The addition of UPFC at

Corresponding author: Muhammad Yousaf Ali Khan 
the weakest bus of the power system improves voltage stability and loading margin [7]. FACTS controllers have a strong effect on static voltage stability in power systems. The voltage stability and loading margin of an electrical network can be increased by the application of FACTS controllers [8]. The selection of the most suitable FACTS device to control the flow of active and reactive power depends upon the performance analysis of different FACTS devices. The application of FACTS controllers for congestion management and voltage support improves the stable operation of the power system. The voltage level can be maintained at its reference value (1pu) by the use of devices like STATCOM and UPFC [9]. The installation of FACTS controllers solves the problems of uneven power flow and transient and dynamic voltage instability. The application of these devices locally is limited by their systematic control and capital cost. The abovementioned problems can be solved locally and economically by using a combination of energy storage systems (ESS) and FACTS devices [10]. The transient stability control ensures the stable operation of the power system in the event of large disturbances. The transient stability of the power system can be improved by applying FACTS controllers [11]. The advancements in the field of FACTS technology introduced many different configurations to control power flow. UPFC can improve the power quality of a system [12]. In order to improve power quality, the performance of UPFC with PI controller and with conventional system has been investigated. The UPFC with PI controller improves the power quality of the power system. Active and reactive power can be controlled effectively by the use of UPFC. The benefits of applying FACTS controllers in AC networks are power flow control, stability and loading margin. Power system performance characteristics can be improved by using several FACTS controllers [13]. As mentioned above, the high initial cost of FACTS controllers limits their applications. However, FACTS devices had provided the most reliable and efficient solutions [14]. The benefits of FACTS controllers in electrical utilities are important but the problems of high losses by using advanced FACTS controllers must also be considered. Flexible and dynamic control of electrical networks is made possible through FACTS devices [15]. The effectiveness of FACTS devices can be examined by applying them to the system in different scenarios. The semiconductor technology can be summarized in the development of these devices. In addition, major real-world installations and utility experiences with and without FACTS controllers can be also examined in order to know the importance of these devices. Power flow in electrical systems can be optimized through FACTS controllers.

\section{PROPOSED MODEL}

Most loads of a power system are inductive in nature and draw reactive power along with active power from the supply source. So, in order to obtain better system results we have to maintain adequate supply of both active and reactive power. The modern electrical power system comprises of a number of generators, transmission lines, transformers and loads. Some transmission systems are more loaded than their rated capacity because of increased power demand. Power transmission lines operate at different voltage levels varying from $110 \mathrm{kV}$ to $800 \mathrm{kV}$ ( $66 \mathrm{kV}$ to $500 \mathrm{kV}$ in Pakistan). The voltages of the power transmission lines are kept high to reduce the losses in transmission lines, while the distribution systems operate below $100 \mathrm{kV}$ for security and convenience reasons associated with the supply of electric power to domestic and industrial loads. The power transmission lines are highly interconnected because of the following economic advantages:

- A tie line control is used to share the generating reserves for interconnected electric power transmission lines.

- The transformers increase or decrease voltage levels according to the required conditions and power transmission lines can operate at different voltages.

AC lines have inherent power flow control as the power flow is determined by the power at the sending end or receiving end. Let us assume a lossless transmission line with negligible line charging. The transmission line equation can be given as:

$$
P=\frac{V_{1} V_{2}}{X} \sin \left(\theta_{1}-\theta_{2}\right)
$$

where $V_{1}$ and $V_{2}$ are the sending end and receiving end voltages, $\theta_{1}$ and $\theta_{2}$ are the voltage angles while $x$ is the reactance of the line. In case of disturbances such as line outage, line trip, generator outage or sudden increase in load, power flow is changed to ensure system reliability and security under these dynamic conditions. The flow of power is changed by the FACTS devices used in the system. Moreover, the flow of power in AC transmission line is controlled to enhance power system transmission capacity.

As the load increases, bus voltage drops and may cross the minimum allowable limit. So the buses operating closer to the limits have a tendency to drop their voltage below $0.95 \mathrm{pu}$ which is a limiting standard. We have to cope with this problem by using FACTS devices which can set and maintain a reference voltage level. Moreover, in case of the contingency of one line, others can become overloaded. The voltage at the buses change and line currents are redistributed throughout the network when a transmission line is switched on or off through circuit breakers. In order to predict a new steady-state, bus voltages and line currents technique of contingency analysis is used. The system planners and operators are more concerned about overloads and under voltages rather than finding the exact values of voltage and current. Due to this reason, largescale network models used for contingency evaluation are not required to be exactly like the models used for fault calculations. In this case, various contingency conditions, their effect on bus voltages and currents and the application of devices are checked. We can maintain power flow across lines by fixing these devices [10]. They will only allow reference power to flow, diverting the remaining power to flow from under-loaded lines. The proposed model shows that these problems come in our selected network and FACTS devices help to solve these problems. UPFC can be used to control the flow of active and reactive power in a transmission system connected to the high voltage side of the network and control the amount of reactive power supplied to the line at the installation point. When a line is switched on or off, line currents are redistributed throughout the network and bus voltages change. The new steady-state bus voltages and line currents can be predicted by what is called the contingency 
analysis program. Although Matlab has some disadvantages, most of the electrical systems can easily be examined through this software. In our case, some options are not available in Matlab for load flow analysis as they are available in other professional software. For example, there is no bus bar available in Matlab. We used three-phase measurement block as a bus bar. In PWS we have the facility to add fields (Voltages, angle, etc.) around the bus but in Matlab this facility is not available. Moreover, in order to calculate the line power flows, we have to adopt a lengthy procedure. However, some important features which are quite helpful in load flow analysis are provided in later versions of Matlab. Large-scale network models used for contingency evaluation, like those used for fault calculations, do not have to be exact because the system planners and operators are more concerned with knowing if overload levels of current and out-of-limit voltages exist than with finding the exact values of those quantities. The simulation of the whole electrical network is carried on Matlab, but in Matlab, load flow analysis does not work with FACTS devices, so to cope with this problem one can develop his own load flow tool for more accuracy. We implemented UPFC from FACTS family on a four bus network. The data obtained from the network including line impedances, transformer parameters, load demand and generation are shown below. UPFC can provide reactive power to the system because it consists of STATCOM which has the ability to generate reactive power according to the network demands. The power grid consists of two power generation substations and one major load centre at bus B3. The first power generation substation (M1) has a rating of $2100 \mathrm{MVA}$ (L3). UPFC is connected between bus number one and two. Without UPFC, active power of bus number two was $663 \mathrm{MW}$ and reactive power was $-122.3 \mathrm{MVAR}$. The generation substation M2 is also connected to the load by a $50 \mathrm{~km}$ line by setting the reference of the active and reactive power of M1 connected to this load by two transmission lines L1 and L2. L1 is $280 \mathrm{~km}$ long and L2 is split into two segments where the active and reactive power are absorbed by the load. The total length of the line L1 is $280 \mathrm{~km}$, line L2 is $300 \mathrm{~km}$ long and line L3 is $50 \mathrm{~km}$. The UPFC measurement block has the set parameters of active power, reactive power and the phase and magnitudes of the voltage values. Both generators are also connected with transformers. The network diagram on Simulink is shown in Figure 1.

\section{RESULTS AND DISCUSSION}

The generation substations M1 and M2 representing 4 and 6 machines of 350MVA respectively have a rating of 1400MVA. The load center of approximately $2200 \mathrm{MW}$ is modeled using a dynamic load only transfer's active power from one line to the other according to the reference which is set for active power in order to simulate the effect of UPFC. It should be noted that the UPFC does not produce active power on bus two, it sets the active power to $763 \mathrm{MW}$ and maintains reactive Power to -122.3 MVAR. However, the shunt compensation devices in the UPFC supply the reactive power to the system. The UPFC basically controls the active power flow. In overload conditions, it allows the flow of active power according to a set reference power, thereby minimizing the contingency. The results with and without UPFC are shown in Tables I-IV and in Figures 2-5.

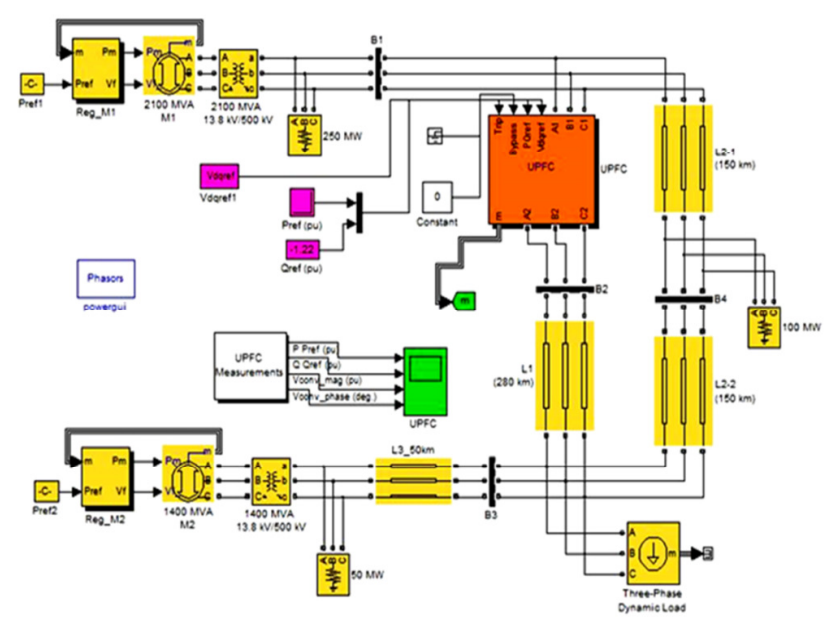

Fig. 1. Network diagram on Simulink

TABLE I. SIMULATION RESULTS WITHOUT UPFC

\begin{tabular}{|c|c|c|c|}
\hline Bus & $\begin{array}{c}\text { Active Power } \\
\text { (MW) }\end{array}$ & $\begin{array}{c}\text { Reactive Power } \\
\text { (MVAR) }\end{array}$ & Voltages (V) \\
\hline B1 & 1337 & -233 & 1.006 \\
\hline B2 & 663.5 & -122.3 & 1.006 \\
\hline B3 & 988.9 & -29.25 & 1.002 \\
\hline B4 & 563.2 & -40.67 & 1.014 \\
\hline
\end{tabular}

TABLE II. SIMULATION RESULTS WITH UPFC

\begin{tabular}{|c|c|c|c|}
\hline Bus & $\begin{array}{c}\text { Active Power } \\
\text { (MW) }\end{array}$ & $\begin{array}{c}\text { Reactive Power } \\
\text { (MVAR) }\end{array}$ & Voltages (V) \\
\hline B1 & 1331 & -294.2 & 1.01 \\
\hline B2 & 762.4 & -122 & 0.9925 \\
\hline B3 & 987 & -10.71 & 0.9988 \\
\hline B4 & 460.3 & -15.92 & 1.017 \\
\hline
\end{tabular}

TABLE III. COMPARISON OF ACTIVE POWER RESULTS

\begin{tabular}{|c|c|c|}
\hline Bus & Without UPFC (MW) & With UPFC (MW) \\
\hline B1 & 1337 & 1331 \\
\hline B2 & 663.5 & 762.4 \\
\hline B3 & 988.9 & 987 \\
\hline B4 & 563.2 & 460.3 \\
\hline
\end{tabular}

TABLE IV. COMPARISON OF REACTIVE POWER RESULTS

\begin{tabular}{|c|c|c|}
\hline Bus & Without UPFC (MVAR) & With UPFC (MVAR) \\
\hline B1 & -233 & -294.2 \\
\hline B2 & -122.3 & -122 \\
\hline B3 & -29.25 & --10.71 \\
\hline B4 & -40.67 & -15.92 \\
\hline
\end{tabular}

Active power is set at $763 \mathrm{MW}$ and the other parameters are changed simultaneously. The active power has a relationship with the voltage angles and the reactive power is changed by changing the voltages of the lines. It can be seen from the Figures that the active power of the bus 1 was $1337 \mathrm{MW}$ without UPFC and it is changed to $1331 \mathrm{MW}$ by incorporating the UPFC between the lines. The reactive power of the bus 1 without UPFC was -233MVAR which has been changed to -294MW and the simultaneous changes in the bus voltages with and without UPFC can be seen. 


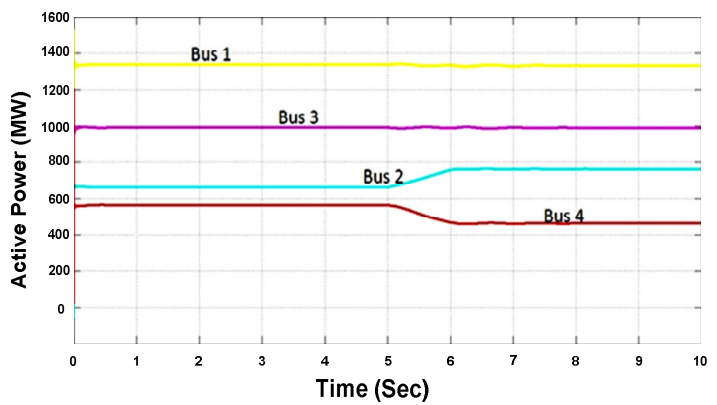

Fig. 2. Active power without UPFC

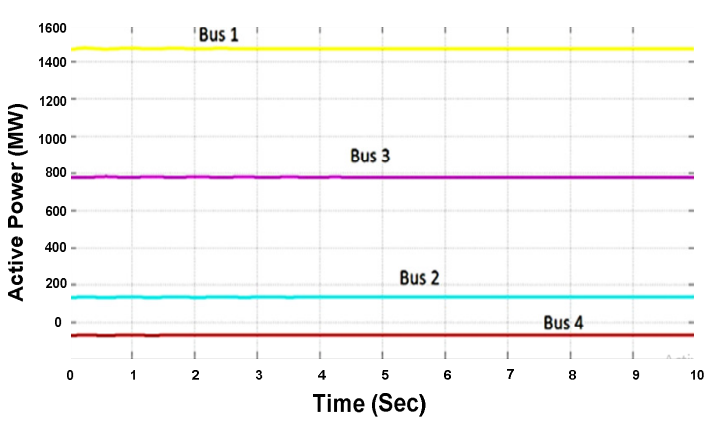

Fig. 3. Active power with UPFC

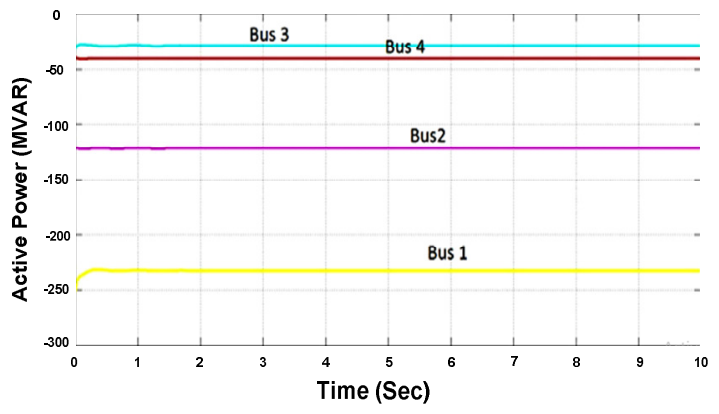

Fig. 4. Reactive power without UPFC

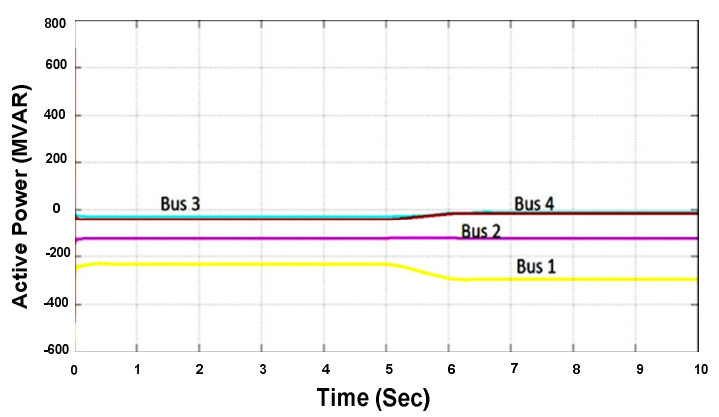

Fig. 5. Reactive power with UPFC

The increase in the active power of the BUS 2 from $663 \mathrm{MW}$ to $763 \mathrm{MW}$ can be seen from the graphs. It should been noted that the reactive power at bus 2 is the same with and without UPFC. This shows that employing UPFC doesn't change the reactive power of the concerned bus. However, reactive power is transformed from a bus to another bus to change the active powers of the buses. The bus voltages in the system have a dynamic range of $10 \%$. If the voltage drops below $0.90 \mathrm{pu}$ or increase above $1.10 \mathrm{pu}$ the system operation will be disturbed. Shunt compensating FACTS devices maintain the voltage range by supplying or absorbing reactive power. Moreover, the active powers are changed at the expense of voltage angles by controlling of voltage angles at the sending and receiving end of the transmission lines.

\section{CONCLUSION}

The flow of power can be controlled in a network through FACTS devices. Basic parameters of a power system like active power, reactive power and voltages can be controlled and adjusted simultaneously by the use of a UPFC. The incorporation of FACTS devices improves the stability of the power system. In Pakistan's WAPDA system, the rapid increase in load and no generation to cope the load has increased load shedding and supply problems through the country. The government has planned to increase the generation capacity but the supply companies faced the problems of line load-ability, environmental constraints, power limits etc. The series controlled compensation provided by FACTS can provide an efficient solution to this problem. With the use of TCSC we can enhance the power transfer capability of the existing lines and hence we can mitigate the problem line load-ability issues. With the application of FACTS, we also provide an additional feature of stability even in post contingency conditions for both transient and steady-state stability issues. So Pakistan transmission companies should install FACTS devices because they will be proved to be beneficial in terms of cost and environmental concern.

\section{REFERENCES}

[1] P. S. Georgilakis, P. G. Vernados, "Flexible AC transmission system controllers: An evaluation", In Materials Science Forum, Vol. 670, pp. 399-406, 2011

[2] J. Dixon, L. Moran, J. Rodriguez, R. Domke, "Reactive power compensation technologies: State-of-the-art review", Proceedings of the IEEE, Vol. 93, No. 12, pp. 2144-2164, 2005

[3] A. Sode-Yome, N. Mithulananthan, K. Y. Lee, "A comprehensive comparison of FACTS devices for enhancing static voltage stability", IEEE Power Engineering Society General Meeting, Tampa, USA, June 24-28, 2007

[4] A. Sode-Yome, N. Mithulananthan, "Comparison of shunt capacitor, SVC and STATCOM in static voltage stability margin enhancement", International Journal of Electrical Engineering \& Education, Vol 41, No. 2, pp. 158-171, 2004

[5] D. Van Hertem, J. Verboomen, R. Belmans, W. L. Kling, "Power flow controlling devices: An overview of their working principles and their application range", IEEE International Conference on Future Power Systems, Amsterdam, Netherlands, November 18, 2005

[6] P. Bresesti, M. Sforna, V. Allegranza, D. Canever, R. Vailati, "Application of Phase Shifting Transformers for a secure and efficient operation of the interconnection corridors", IEEE Power Engineering Society General Meeting, Denver, USA, June 6-10, 2004

[7] N. S. Do, M. M. Gouvea Jr, "Voltage stability enhancement in power systems with automatic facts device allocation", Energy Procedia, Vol. 107, pp. 60-67, 2017

[8] B. Bhattacharyya, V. K. Gupta, S. Kumar, "UPFC with series and shunt FACTS controllers for the economic operation of a power system", Ain Shams Engineering Journal, Vol. 5, No. 3, pp. 775-787, 2014

[9] M. A. Kamarposhti, H. Lesani, "Effects of STATCOM, TCSC, SSSC and UPFC on static voltage stability", Electrical Engineering, Vol. 93, No. 1, pp. 33-42, 2011 
[10] Z. Yang, C. Shen, L. Zhang, M. L. Crow, S. Atcitty, "Integration of a StatCom and battery energy storage", IEEE Transactions on Power Systems, Vol. 16, No. 2, pp. 254-260, 2001

[11] D. Murali, M. Rajaram, N. Reka, "Comparison of FACTS devices for power system stability enhancement", International Journal of Computer Applications, Vol. 8, No. 4, pp. 30-35, 2010

[12] S. E. Mubeen, R. K. Nema, Gayatri Agnihotri, "Power flow control with UPFC in power transmission system", International Journal of Electrical and Computer Engineering, Vol. 2, No. 11, pp. 2507-2511, 2008

[13] J. J. Paserba, "How FACTS controllers benefit AC transmission systems", IEEE Power Engineering Society General Meeting, Denver, USA, June 6-10, 2004

[14] N. Acharya, A. Sode-Yome, N. Mithulananthan, "Facts about flexible AC transmission systems (FACTS) controllers: practical installations and benefits", Australasian Universities Power Engineering Conference (AUPEC), Hobart, Tasmania, Australia, September 25-28, 2005

[15] A. K. Mohanty, A. K. Barik, "Power system stability improvement using facts devices", International Journal of Modern Engineering Research, Vol. 1, No. 2, pp. 666-672, 2011 